\title{
Research on Location Selection of Shared Vehicle Charging Station Based on Analytic Hierarchy Process and Fuzzy Evaluation Method
}

\author{
Rongxu Zhang, Bo Zhao \\ Shanghai University of Engineering Science, Shanghai, China \\ Email: 15901707080@163.com
}

How to cite this paper: Zhang, R.X. and Zhao, B. (2018) Research on Location Selection of Shared Vehicle Charging Station Based on Analytic Hierarchy Process and Fuzzy Evaluation Method. Open Access Library Journal, 5: e4899.

https://doi.org/10.4236/oalib.1104899

Received: September 11, 2018

Accepted: September 25, 2018

Published: September 28, 2018

Copyright ( 2018 by authors and Open Access Library Inc.

This work is licensed under the Creative

Commons Attribution International

License (CC BY 4.0).

http://creativecommons.org/licenses/by/4.0/

(c) (1) Open Access

\begin{abstract}
In view of the incompleteness of the methods used in the location selection of today's shared car charging stations, the author proposes to combine the two methods of AHP and fuzzy evaluation to construct an evaluation index system and a fuzzy level evaluation model. The two alternative electric vehicle charging station addresses are comprehensively evaluated to achieve the most preferred address. Practice has proved that this method has a high degree of accuracy.
\end{abstract}

\section{Subject Areas}

Mechanical Engineering

\section{Keywords}

Shared Car, Charging Station, Analytic Hierarchy Process, Fuzzy Evaluation Method, Evaluation Index System

\section{The Basic Idea of Fuzzy Comprehensive Evaluation Method}

The fuzzy comprehensive evaluation method is a general judgment that can reasonably synthesize these attributes or factors for things with multiple attributes or their overall advantages and disadvantages affected by many factors. The fuzzy comprehensive evaluation model generally consists of six elements: the evaluation object set, the evaluation object impact factor set, the importance index of each factor, the evaluation level set of the influence factor, the fuzzy eval- 
uation matrix, and the comprehensive evaluation result. The location of the car-sharing site is affected by a variety of qualitative and quantitative factors, and the six elements can be analyzed by the fuzzy comprehensive evaluation method.

\section{Evaluation Model for Sharing Car Site Selection}

1) Analysis of evaluation factors and establishment of indicator system. Demand is the first consideration for the development of car sharing, and it is also a factor to consider when site selection [1]. The demand for shared cars is influenced by population density and the willingness of travellers to choose, and the density of the population is affected by nearby public places, residential areas and businesses [2]. Travel expenses, time and convenience are the main factors that travellers choose to share.

For shared sites, vehicle costs, land costs, management costs, and technology costs are not small and need to be carefully considered. This paper attributes these factors to the impact of the economic side on site selection.

Coordination is also a very important factor. In the selection of sites, we must fully consider the coordination with other public transportation, so that the sharing of cars can be implemented smoothly. In addition, the construction of shared car sites involves the use of land and the supporting facilities of the surrounding facilities [3], so it should be coordinated with the overall planning of the city. At the same time, it is necessary to consider coordination with the sites already built to avoid redundant construction and waste resources.

Finally, car sharing sites must also consider their social benefits, mainly from three aspects: the satisfaction of consumer travel needs, the degree of mitigation of traffic congestion, and the impact on the natural environment.

2) Establish an indicator weight set.

a) Construct a judgment matrix. The Analytic Hierarchy Process (AHP) [4] divides the factors in a complex problem into related and ordered levels to make them organized. A quantitative representation of the relative importance of each of the two elements in each level is given based on objective judgment [5].

Let the judgment matrix $A=(a i j)(i, j=1,2, \ldots, n)$, where aij represents the relative importance of the $i$ element to the $j$ element, and $a i j>0$, $a i j=1 / a j i$, $a i i=$ 1. This paper compares the different indicators using the 1 - 9 scale method proposed by American operations researcher Professor T.L. Saaty. Judging the comparison values of the elements in the matrix, generally $1,3,5,7,9$ respectively indicate that $i$ is equally important, slightly important, significant, strong, and extremely important relative to the $j$ element, 2, 4, 6, 8 The median value of the adjacent judgment.

b) Calculation of indicator weights. Each column of the judgment matrix A is normalized, and the sum of each line after normalization is obtained [6], and then the sum is normalized, that is, the weight of the upper layer index corresponding to each index is obtained. In the actual operation, MATLAB is used to solve the eigenvector corresponding to the maximum eigenvalue of the matrix 
A, and the consistency test is performed. If passed, the eigenvectors are normalized to obtain the weight vector $\mathrm{W}$ of each factor.

c) Consistency test. Since the judgment matrix is derived from the importance of the two elements, there is a certain error. To ensure the reliability of the calculation results, a consistency check is required. The test formula is: $\mathrm{CR}=\mathrm{CI} / \mathrm{RI}$. Where $\mathrm{CI}=\left(\lambda_{\max }-\mathrm{n}\right) /(\mathrm{n}-\mathrm{I}), \lambda_{\max }$ is the maximum eigenvalue of the judgment matrix $\mathrm{A}, \mathrm{n}$ is the dimension of the judgment matrix, $\mathrm{CR}$ is the consistency ratio, and RI is the random consistency index (see Table 1).

If $\mathrm{CR}<0.1$, then the judgment matrix satisfies the consistency test; otherwise, the judgment matrix needs to be adjusted.

d) Sharing the weight calculation results of each indicator of the location of the car site [7]. After soliciting the opinions of relevant experts and combining the actual research situation, the judgment matrix at all levels is obtained. According to the above steps, the weight results of each indicator are calculated as shown in Tables 2-6. It is seen from the calculation results that all the judgment matrices satisfy the consistency test.

Table 1. Values of random consistency indicators.

\begin{tabular}{cccccccccccc}
\hline$n$ & 1 & 2 & 3 & 4 & 5 & 6 & 7 & 8 & 9 & 10 & 11 \\
\hline $\mathrm{RI}$ & 0 & 0 & 0.58 & 0.90 & 1.12 & 1.24 & 1.32 & 1.41 & 1.5 & 1.19 & 1.51 \\
\hline
\end{tabular}

Table 2. Comprehensive evaluation judgment matrix therefore, each indicator weight has certain reliability.

\begin{tabular}{ccccccc}
\hline 0 & $\mathrm{C} 1$ & $\mathrm{C} 2$ & $\mathrm{C} 3$ & $\mathrm{C} 4$ & Index weight & Consistency test \\
\hline $\mathrm{C} 1$ & 1 & 1 & 1 & 1 & 0.250 & $\lambda_{\max }=4$ \\
$\mathrm{C} 2$ & 1 & 1 & 1 & 1 & 0.250 & $\mathrm{CI}=0$ \\
$\mathrm{C} 3$ & 1 & 1 & 1 & 1 & 0.250 & $\mathrm{CR}=0$ \\
$\mathrm{C} 4$ & 1 & 1 & 1 & 1 & 0.250 & Satisfy consistency \\
\hline
\end{tabular}

Table 3. Demand judgment matrix.

\begin{tabular}{ccccc}
\hline C1 & D1 & D2 & Indicator weight WC1 & Consistency test \\
\hline D1 & 1 & 2 & 0.667 & $\lambda_{\max }=2$ \\
D2 & $1 / 2$ & 1 & 0.333 & $\begin{array}{c}\mathrm{CI}=0, \mathrm{CR}=0 \\
\text { Meets consistency }\end{array}$ \\
\hline
\end{tabular}

Table 4. Economic judgment matrix.

\begin{tabular}{ccccccc}
\hline C2 & D3 & D4 & D5 & D6 & Indicator weight WC2 & Consistency test \\
\hline D3 & 1 & 1 & $1 / 2$ & $1 / 3$ & 0.141 & $\lambda_{\max }=4.01$ \\
D4 & 1 & 1 & $1 / 2$ & $1 / 3$ & 0.141 & RI $=0.9$ \\
D5 & 2 & 2 & 1 & $1 / 2$ & 0.263 & CR $=0.023<0.1$ \\
D6 & 3 & 3 & 2 & 1 & 0.455 & Satisfy consistency \\
\hline
\end{tabular}


Table 5. Coordination judgment matrix.

\begin{tabular}{cccccc}
\hline C3 & D7 & D8 & D9 & Indicator weight WC3 & Consistency test \\
\hline D7 & 1 & 2 & 3 & 0.540 & $\lambda_{\max }=3.009$ \\
D8 & $1 / 2$ & 1 & 2 & 0.297 & $\mathrm{CI}=\left(\lambda_{\max }-n\right) /(n-1)=0.046$ \\
D9 & $1 / 3$ & $1 / 2$ & 1 & 0.163 & $\mathrm{CR}=0.027<0.1$ Meets consistency \\
\hline
\end{tabular}

Table 6. Travelers choose to share the car willingness judgment matrix.

\begin{tabular}{cccccc}
\hline D2 & E4 & E5 & E6 & Indicator weight WD2 & Consistency test \\
\hline E4 & 1 & 2 & 3 & 0.528 & $\lambda_{\max }=3.054$ \\
E5 13 & $1 / 2$ & 1 & 3 & 0.332 & $\mathrm{RI}=0.58$ \\
E6 & $1 / 3$ & $1 / 3$ & 1 & 0.140 & $\mathrm{CR}=0.0155<0.1$ Satisfy consistency \\
\hline
\end{tabular}

\section{Establish a Fuzzy Comprehensive Evaluation Level Set V}

The evaluation level set is a set of various evaluation results that the judges may make for the evaluation factors, $V=\{v 1, v 2, \cdots, v m\}, V$ represents the evaluation set, and vi represents the evaluation index. The evaluation level established in this paper is $V=\{v 1, v 2, \ldots, v m\}, v=$ It is very suitable for building a site, suitable for building a site, generally suitable for building a site, less suitable for building a site [8], and not suitable for building a site.

\section{Establish a Fuzzy Evaluation Matrix R}

After constructing the evaluation level set $V$, it is necessary to quantify the evaluated things one by one from the single factor $u i(i=1,2, \cdots, n)$, that is, to determine the graded subset $v i$ of the evaluated things from the single factor $u i$, the membership degree, and then the fuzzy evaluation matrix $\mathrm{R}$. The element rij in the matrix $\mathrm{R}$ represents the degree of membership of $y j$ in a given thing from the factor vi. The performance of an evaluated thing in a certain factor $v i$ is described by the fuzzy vector $(\mathrm{R} / \mathrm{ui})=($ ri1, ri2, $\cdots$, rim $)$.

\section{Fuzzy Comprehensive Evaluation Result Vector B}

Due to the complexity of the location of the car sharing site and the numerous factors involved in the evaluation, in order to make the results scientific and reasonable, it is necessary to fully consider the influence of various factors and comprehensively reflect the information of the single factor evaluation. This requires that all the influencing factors should be balanced according to the weight of weights [9]. This paper chooses the weighted average type fuzzy operator.

\section{Application Examples}

Taking the location evaluation point $\mathrm{P}$ of an urban car sharing site as an example, the comprehensive evaluation is carried out by combining AHP and fuzzy comprehensive evaluation method, and the frequency of each factor corres- 
ponding to each evaluation level is obtained by the method of summarizing the results of the experts, and normalized [10]. The processing can obtain the membership evaluation matrix corresponding to each level of each factor of the site $\mathrm{P}$ as follows: The evaluation matrix of the three influencing factors of the population flow size is:

$$
R_{D 1}=\left(\begin{array}{ccccc}
0.2 & 0.6 & 0.2 & 0 & 0 \\
0.3 & 0.6 & 0.1 & 0 & 0 \\
0.1 & 0.5 & 0.3 & 0.1 & 0
\end{array}\right)
$$

The evaluation matrix for the three factors that influence consumers' choice of car sharing is:

$$
\begin{gathered}
R_{D 2}=\left(\begin{array}{ccccc}
0.2 & 0.5 & 0.2 & 0.1 & 0 \\
0.3 & 0.6 & 0.1 & 0 & 0 \\
0.1 & 0.4 & 0.4 & 0.1 & 0
\end{array}\right) \\
B_{D 1}=W_{D 1} R_{D 1}=\left(\begin{array}{lllll}
0.20000 & 0.5750 & 0.2000 & 0.0250 & 0
\end{array}\right) \\
B_{D 2}=W_{D 2} R_{D 2}=\left(\begin{array}{lllll}
0.2192 & 0.5192 & 0.1948 & 0.0668 & 0
\end{array}\right)
\end{gathered}
$$

After the synthesis operation, a comprehensive evaluation decision matrix is obtained:

$$
R=\left(\begin{array}{ccccc}
0.206 & 0.556 & 0.198 & 0.038 & 0 \\
0.073 & 0.331 & 0.309 & 0.200 & 0.054 \\
0.146 & 0.429 & 0.270 & 0.100 & 0.054 \\
0.163 & 0.400 & 0.225 & 0.172 & 0.036
\end{array}\right)
$$

The weight vector of the comprehensive evaluation $\mathrm{W}=\mathrm{W} 0=(0.250,0.250$, $0.250,0.250,0.25)$ Therefore, the fuzzy evaluation result of the suitability of establishing a shared car site at site $\mathrm{P}$ is: $\mathrm{B}=\mathrm{W} \cdot \mathrm{R}=(0.14750 .42940 .25090 .1283$ 0.0440). Each element in B indicates the appropriate level of this shared car site corresponds to the degree of membership of each level in the evaluation set. According to the principle of maximum membership, the second item has the largest index, indicating that the appropriate level for site $\mathrm{P}$ to establish a shared car is "fit". The evaluation result obtained by the multi-level fuzzy comprehensive evaluation is a fuzzy vector $B=(b 1, b 2, \cdots, b n)$, that is, the membership vector of the evaluation object belonging to each evaluation level. When comparing and sorting multiple evaluation objects, it is necessary to calculate the comprehensive score of each evaluation object, and the defuzzification can be performed by the hierarchical parameter method [11]. The evaluation score is based on the commonly used 100-point system. The scores corresponding to the original 5 grades are $(90,100),(70,90),(50,70],(20,50],[0,20] 5$ evaluation intervals. Select the upper bound of each level of the evaluation interval as the parameter of each level, indicating the boundary between the levels The evaluation result is listed as $\mathrm{C}$ $=(\mathrm{c} 1, \mathrm{c} 2, \mathrm{c3}, \mathrm{c4}, \mathrm{c5}) \mathrm{T}=(20,50,70,90,100) \mathrm{T}$ with respect to the parameter ranking of each evaluation level, and thus the comprehensive score of the site $\mathrm{P}$ is $\mathrm{B} \cdot \mathrm{C}=78.2540$. 


\section{Conclusion}

There are many factors involved in the location of shared car sites, and the levels are also complex. This paper analyzes the influencing factors of the location of shared car sites, uses the analytic hierarchy process to establish an index evaluation system for the location of shared car sites, and determines the weights of each index, combined with fuzzy. The comprehensive evaluation model calculates the suitability membership vector $\mathrm{B}$ of the shared vehicle alternative site $\mathrm{P}$, and uses the inverse fuzzy method to obtain the comprehensive score of the candidate site $\mathrm{P}$, indicating that the multiple scores of each site can be selected according to the comprehensive score of each site, to choose the best. This paper verifies the practicability and feasibility of the method by using examples. It is believed that it can provide a more scientific and feasible method for the relevant decision-making departments to plan and locate the site at the car sharing site.

\section{Conflicts of Interest}

The authors declare no conflicts of interest regarding the publication of this paper.

\section{References}

[1] Xie, L.W. (2012) Adaptive PSO Algorithm Based Optimal Planning of Charging Station for Electric Vehicle. Shanxi Electric Power, No. 11, 34-37.

[2] Kou, L.F., Liu, Z.F. and Zhou, H. (2010) Modeling Algorithm of Charging Station Planning for Regional Electric Vehicle. Modern Electric Power, 27, 44-48.

[3] Wang, F.L., Sun, K.H. and Li, Y.Q. (2013) Demand Forecast of Electric Vehicle Charging Stations Based on Customer Classification. Heilongjiang Electric Power, 35, 132-134.

[4] Qian, B., Shi, D.Y., Xie, P.P., et al. (2014) Optimal Planning of Battery Charging and Exchange Stations for Electric Vehicles. Automation of Electric Power Systems, 38, 64-69.

[5] Guo, C.L. and Xiao, X.L. (2013) Planning Method and Model of Electric Vehicle Charging Infrastructure. Automation of Electric Power Systems, 37, 70-75.

[6] Liu, Z.P., Wen, F.S., Xue, Y.S., et al. (2012) Optimal Siting and Sizing of Electric Vehicle Charging Stations. Automation of Electric Power Systems, 36, 54-59.

[7] Tang, X.G., Liu, J.Y., Liu, Y.B., et al. (2012) Electric Vehicle Charging Station Planning Based on Computational Geometry Method. Automation of Electric Power Systems, 36, 24-30.

[8] Liu, Z.F., Zhang, W. and Wang, Z.L. (2012) Optimal Planning of Charging Station for Electric Vehicle Based on Quantum PSO Algorithm. Proceedings of the CSEE, 32, 39-45.

[9] Zhang, T. (2008) Research on the Siting for Logistic Center Based on Analytic Hierarchy Process. Wuhan University of Science and Technology, Wuhan.

[10] Liao, P. (2010) Evaluation on Tourism Bidding Scheme Based on the Combination of AHP and Fuzzy Method. Seeker, No. 2, 15-17.

[11] Mehar, S. and Senouci, S.M. (2013) An Optimization Location Scheme for Electric Charging Stations. 2013 International Conference on Smart Communications in Network Technologies, Paris, 17-19 June 2013, 1-5. 